\title{
CLASSIFICAÇÃO FUNCIONAL DE INDIVÍDUOS COM PARALISIA CEREBRAL DE ACORDO COM A ESCALA DE AVALIAÇÃO GMFCS
}

\author{
Amanda Cristina Araújo Rosa' \\ Márcio Rodrigues de Matos ${ }^{2}$
}

Resumo: A encefalopatia crônica não progressiva é um dos problemas mais recorrentes na fase do desenvolvimento encefálico e acarreta disfunção predominantemente sensoriomotora. A escala GMFCS foi criada com o objetivo de avaliar a funcionalidade motora desses indivíduos, atendendo à necessidade de um sistema padronizado de classificação embasado nas habilidades e limitações. $A$ amostra deste estudo será composta por 10 crianças com idade média de 7,5 anos que possuírem, isoladamente, diagnóstico médico de PC. Os participantes serão catalogados segundo a sua topografia motora e classificados de acordo com os cinco níveis da escala GMFCS. A aplicação da escala irá proporcionar aos fisioterapeutas que atuam na área de neurologia infantil uma avaliação que permita direcionar cada indivíduo no seu nível motor funcional, contribuindo para que o planejamento fisioterapêutico seja baseado na mobilidade e locomoção desses pacientes.

Palavras-chave: Fisioterapia; Paralisia cerebral; Escala GMFCS.

\footnotetext{
${ }^{1}$ Fisioterapia/Universidade Paulista, Brasil. E-mail: amandacris.rosa@yahoo.com.br.

2 Fisioterapia/Universidade Paulista, Brasil. E-mail: marciomatos_fisio@yahoo.com.br.
} 